\title{
RUBLACK, Hans-Christoph, Die lutherische Konfessionaliserung in Deutschland (Wissenschaftiches Symposion des Vereins für Reformationsgeschichte)
}

\section{Gérald Chaix}

\section{(2) OpenEdition}

\section{Journals}

Édition électronique

URL : http://journals.openedition.org/ifha/2092

DOI : $10.4000 /$ ifha.2092

ISSN : 2198-8943

\section{Éditeur}

IFRA - Institut franco-allemand (sciences historiques et sociales)

Référence électronique

Gérald Chaix, «RUBLACK, Hans-Christoph, Die lutherische Konfessionaliserung in Deutschland (Wissenschaftiches Symposion des Vereins für Reformationsgeschichte)», Revue de l'IFHA [En ligne], Date de recension, mis en ligne le 01 janvier 1993, consulté le 22 septembre 2020. URL : http:// journals.openedition.org/ifha/2092 ; DOI : https://doi.org/10.4000/ifha.2092

Ce document a été généré automatiquement le 22 septembre 2020.

(CIFHA 


\title{
RUBLACK, Hans-Christoph, Die lutherische Konfessionaliserung in Deutschland (Wissenschaftiches Symposion des Vereins für Reformationsgeschichte)
}

\author{
Gérald Chaix
}

1 Après les Actes $\mathrm{du}$ colloque consacré par le dynamique Verein für Reformationsgeschichte à la "deuxième Réformation " (1985), autrement dit à la Réforme calviniste, voici ceux du colloque réuni sur le thème de l'« orthodoxie luthérienne » (1988), en attendant ceux du colloque portant sur la confessionnalisation catholique, prévu à Augsbourg en septembre 1993.

Comblant une importante lacune historiographique, ce gros volume fournit un excellent état de la question. Un premier groupe de contributions présente successivement l'historiographie du sujet (H.C. Rublack, pp. 13-32, qui esquisse la variété des problèmes que pose la question abordée par ce colloque, et J. Wallmann, pp. 33-53, qui oppose notamment l'approche juridique de M. Heckel à celle, plus sociale, de H. Schilling) et les enjeux théologiques (W. Sparn, pp. 54-82, qui étudie plus spécialement la crise de la piété, et J. Baur, pp. 83-124, qui traite de la christologie luthérienne). Un second groupe de textes traite des enracinements géographiques de l'orthodoxie (du point de vue du droit avec M. Heckel, pp. 130-162, avec l'exemple territorial du duché de Braunschweig (Brunswick)-Wolfenbüttel, de 1589 à 1613, abordé par L. Schorn-Schütte pp. 163-194, et l'exemple urbain de Bâle trop rapidement esquissé par H.R. Guggisberg, pp. 199-201). Un troisième groupe rassemble de petites monographies sur Chytraeus (Rudolf Keller, pp. 235-247), Andreas Musculus (E. Koch, pp. 250-270), J. Arndt (H. Schneider, pp. 274-298, et W. Sommer, pp. 299-311). Un quatrième groupe traite des « lieux » de l'orthodoxie: l'éthique sociale (M. Honecker, pp. 316-340), la prédication (H.-C. Rublack, pp. 344-395) et l'effort de « discipline sociale 
» qui prend la forme d'un « ordre moral » renforcé (M. Brecht, pp 400-420). Enfin, un cinquième groupe examine quelques uns des moyens mis en oeuvre: les livres de prière (B. Vogler, pp. 424-434), les livres de cantique (P. Veit, pp. 435-454), le jubilé saxon de 1617 dans lequel Heinrich Schütz joue, à Dresde, le premier rôle (H. RobinsonHammerstein, pp. 460-494), et l'art luthérien entre 1550 et 1650 (D. Koepplin, pp. 495-494, avec d'abondantes illustrations). L'article de H. Lehmann (pp. 545-554), consacré à l'eschatologie luthérienne, sert en quelque sorte de conclusion à cet excellent ensemble complété par la publication des discussions et bien sûr par un double index (matière et noms).

3 Gérald CHAIX 